\title{
Contralateral comparison of blue-filtering and non-blue-filtering intraocular lenses: glare disability, heterochromatic contrast, and photostress recovery
}

\author{
This article was published in the following Dove Press journal: \\ Clinical Ophthalmology \\ 10 December 2010 \\ Number of times this article has been viewed
}

\author{
Billy R Hammond Jr' \\ Lisa M Renzi' \\ Sohel Sachak ${ }^{2}$ \\ Stephen F Brint ${ }^{3}$ \\ 'Vision Sciences Laboratory, \\ University of Georgia, Athens, \\ Georgia; ${ }^{2} \mathrm{Alcon}$ Research Ltd, Fort \\ Worth, Texas; ${ }^{3}$ Brint Custom Vision, \\ Metairie, Louisiana, USA
}

Correspondence: Billy R Hammond Jr Vision Sciences Laboratory, University of Georgia,Athens, GA 30602-3013, USA $\mathrm{Tel}+\mathrm{I} 7065424812$

Fax +I 7065423275

Email bhammond@uga.edu
Purpose: To compare visual performance in eyes with intraocular lenses (IOLs) that filter short-wave blue light versus contralateral eyes with IOLs that do not filter visible blue light. Methods: In this prospective, assessor-masked study that was conducted at five clinics in the US, eligible candidates were at least 12 months postimplantation of a control IOL and a contralateral IOL that filtered blue light. Glare disability was defined as the intensity of a white-light annulus that obscured a subject's ability to see a central target. Heterochromatic contrast thresholds were defined as the intensity of a blue-light disk that obscured a central target. Photostress recovery time was the duration required to regain sight of the target after a five-second flash of annulus light.

Results: Fifty-two subjects were evaluated. Mean glare disability was significantly less $(P=0.04)$ in the blue-filtering IOL group $\left(1.97 \pm 0.44 \log \mu \mathrm{W} / \mathrm{cm}^{2}\right)$ than in the control group $\left(1.88 \pm 0.43 \log \mu \mathrm{W} / \mathrm{cm}^{2}\right)$. Mean heterochromatic contrast threshold was significantly higher $(P=0.0003)$ in the blue-filtering IOL group $\left(0.36 \pm 0.43 \log \mu \mathrm{W} / \mathrm{cm}^{2}\right)$ than in the control IOL group $\left(0.15 \pm 0.49 \log \mu \mathrm{W} / \mathrm{cm}^{2}\right)$. Geometric mean photostress recovery time was significantly faster $(P=0.02)$ in the blue-filtering IOL group ( $21 \pm 3$ seconds) than in the control IOL group (26 \pm 3 seconds).

Conclusions: Glare disability was significantly lower, heterochromatic contrast threshold was significantly better, and recovery from photostress was significantly faster in the eyes with bluefiltering IOLs than in the contralateral control eyes with IOLs that did not filter blue light.

Keywords: blue light, filter, glare, intraocular lens, photostress, retina

\section{Introduction}

The idea that intraocular blue-light filters could improve visual function has been posited for many decades. In 1933, Walls and Judd noted the preponderance of intraocular blue-light filters across many species of vertebrates and noted that "scattered light, in nature, is largely of short wave-lengths; if sufficiently bright a true glare results". Therefore, they believed that intraocular blue-light filters could improve visual function by reducing glare discomfort and 'dazzle' and by enhancing contrast. ${ }^{1,2}$ Glare refers generally to a condition where individuals are exposed to a light source, either direct or indirect, that is in excess of their adaptive state. Such light can cause both discomfort and disability (a reduction in visual performance). As originally noted by Walls and Judd, ${ }^{1,2}$ light in the short-wave region of the visible spectrum, blue light, has proven to be particularly deleterious for inducing discomfort ${ }^{3}$ and masking visual targets. ${ }^{4}$ 
Another way that blue-light filters might improve visual performance is by enhancing contrast, an idea that was originally reviewed by Luckiesh in $1915 .{ }^{5}$ In 1972, Luria demonstrated this effect by showing that the threshold for a yellow increment flash on a blue background was reduced when viewed through a blue-absorbing filter. ${ }^{6}$ More recently, Wolffsohn et al confirmed this effect using contrast measures. ${ }^{7}$ The degree of contrast enhancement varied among studies of filters with different spectral characteristics. ${ }^{8-11}$ For optimum enhancement, some research supported blocking wavelengths shorter than $450 \mathrm{~nm}$ but not longer than $480 \mathrm{~nm} .{ }^{12,13}$ This recommended absorbance profile is similar to the natural crystalline lens, ${ }^{14}$ as shown in Figure 1. The contrast-enhancing effects that were measured with blue-filtering lenses arose because the filters reduced the luminance of the background relative to the target, which increased contrast and therefore increased the detectability of the central target. These simple laboratory situations are a good description of many visual situations outdoors. The preponderance of Rayleigh scattered light (seen as 'blue haze' and blue sky light) creates a natural situation where many targets are viewed on short-wave (blue) backgrounds. ${ }^{15}$

As with extraocular filters and native intraocular filters, blue-filtering intraocular lenses (IOLs) that have an absorbance profile similar to the crystalline lens have also demonstrated enhancement of some aspects of visual performance. ${ }^{16}$ The blue-light filtering properties of these IOLs were originally designed to be similar to healthy crystalline lenses (see Figure 1), in order to protect the retina from photodamage. ${ }^{17}$ In addition, these blue-filtering IOLs also reduced glare disability and improved photostress

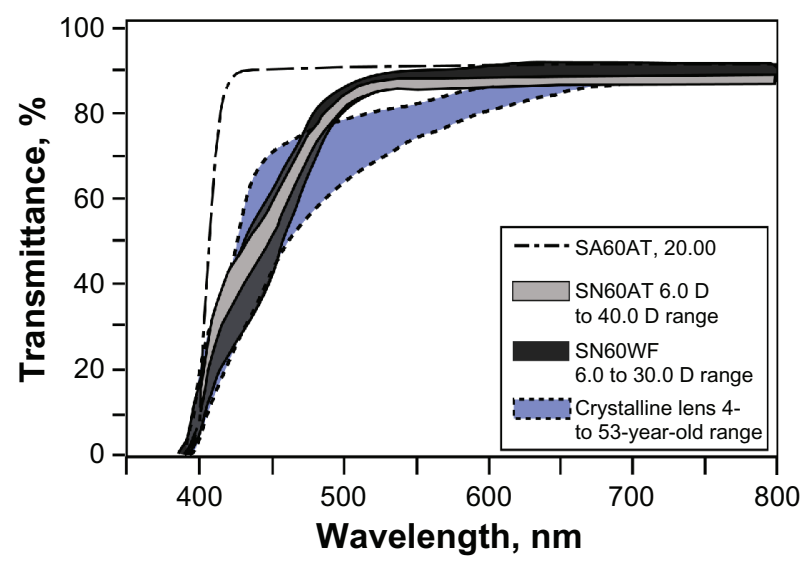

Figure I Transmission spectra of the natural crystalline lens and of the intraocular lens models under investigation. Copyright (c) 2010, Association for Research in Vision and Ophthalmology. Reproduced with permission from Boettner and Wolter. Transmission of the ocular media. Invest Ophthalmol Vis Sci. 1962; I (6):776-783. ${ }^{14}$ Spectra are redrawn from package inserts of intraocular lenses with permission from Alcon Laboratories, Inc. recovery (relative to a lens that filters only ultraviolet light). ${ }^{16}$ The present study replicates our earlier study of subjects with blue-light filtering IOLs versus subjects with control IOLs, ${ }^{16}$ with some important modifications. First, we have added an assessment of heterochromatic contrast threshold (longerwave target against a shorter-wave blue background). Also, rather than using a between-subject design (ie, comparing subjects with blue-filtering IOLs with subjects with IOLs that did not filter visible light), the present study used a withinsubject (contralateral) design. All subjects had an implant that filtered both ultraviolet and blue light in one eye and had an ultraviolet-only filtering implant in the other eye, so that all subjects served as their own controls. These more thorough and rigorously controlled experiments were designed to measure the glare disability, photostress recovery, and heterochromatic contrast thresholds more conclusively in eyes with blue-light filtering IOLs versus eyes with control IOLs.

\section{Subjects and methods}

In this cross-sectional, prospective, multicenter study, participating clinicians reviewed their charts to identify eligible candidates who were at least 12 months postimplantation of the appropriate contralateral IOLs. All subjects were required to have a monofocal IOL that filtered only ultraviolet light (AcrySof IOL model SA60AT; Alcon Laboratories, Inc, Fort Worth, TX, USA) in one eye. In the contralateral eye, subjects were required to have a monofocal IOL with a chromophore that filtered both ultraviolet light and short-wave blue light (AcrySof Natural IOL, model SN60AT; Alcon) or (AcrySof IQ Aspheric Natural IOL, model SN60WF; Alcon). Figure 1 shows the transmission spectra of the SA60AT, SN60AT, and SN60WF IOLs, as provided in the package inserts (AcrySof IQ Aspheric Natural IOL Product Information, 2005, and AcrySof Natural Single-Piece IOL Product Information, 2007; Alcon).

Subjects were required to be at least 21 years of age, in good ocular health, and able to perform the testing competently. Subjects who agreed to visit an investigative clinic were screened for a defined list of ocular health inclusion criteria, including the following: corneal health (no dystrophy, irregular astigmatism, or prior corneal surgery), retinal health (no macular degeneration, previous detachment, or diabetic retinopathy), optic nerve health (no atrophy), iris health (no clinical miosis), and overall ocular health (no ocular disease and/or condition that could compromise study results). Slit-lamp examinations were used to confirm the presence of clear ocular media and the absence of clinically significant posterior capsule opacification. Subjects were excluded from participation if they had any conditions that 
could be exacerbated, triggered, or worsened by exposure to high-intensity light. Baseline measures included manifest refraction and uncorrected and corrected distance visual acuity.

This study was approved by the Sterling Institutional Review Board (Atlanta, GA, USA) for all participating clinical sites. The experimental procedures adhered to the tenets of the Declaration of Helsinki. Subjects were informed about the aims and methods of the study, and all subjects signed a statement of informed consent.

\section{Apparatus}

A two-channel Maxwellian-view optical system, which was similar to previously described systems, ${ }^{4,18-20}$ was constructed at each clinic, disassembled after use, and reassembled at the next clinic. Figure 2 shows a schematic of the system. The glare source (annulus/disk) and the visual target were produced by a dual-port xenon-arc and halogen lamp as the light source (Jintan Jinyang Medical Instruments, China). Alignment of the subject's eye with the optical system was maintained with forehead rests and a dental impression bite bar that was custom-fit for each subject. An auxiliary optical channel with magnifying lenses was used to monitor the pupil during testing to ensure proper fixation and sustained alignment. The same apparatus, with small variations, was used to test glare disability, contrast threshold, and photostress recovery.

All photometric calibrations were performed using a PR-650 SpectraScan Colorimeter (Photo Research, Inc, Chatsworth, CA). Wedge and neutral density radiometric calibrations were performed by using a Graseby Optronics United Detection Technology (UDT) instrument
(Orlando, FL). The same UDT instrument was used before every experimental session and at every clinical site to ensure that the total light output of the optical system remained constant and consistent at all clinical sites.

\section{Visual target}

The visual target was the same in all tests (glare disability, photostress recovery, and heterochromatic contrast threshold). The target was produced by the $100 \mathrm{~W}$ halogen bulb of the dual-port source. The halogen bulb had an emission spectrum as shown in Figure 3 (as assessed by the SpectraScan colorimeter). The emission spectrum had a peak radiance at $645 \mathrm{~nm}$ and a chromaticity of $\mathrm{u}^{\prime}=0.21$ and $\mathrm{v}^{\prime}=0.50$ on the color space definition, which was established by the International Commission on Illumination (Commission Internationale

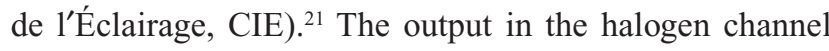
was maintained at constant energy and was checked by a dedicated radiometer at the beginning and end of each clinic visit. The visual target that was produced in the halogen channel was composed of a $3.1^{\circ}$ diameter disk that contained a sine-wave grating with a spatial frequency of eight cycles/ degree (produced by a sine-wave on clear glass; Rolyn Optics, Covina, CA, USA). The halogen channel was shuttered during testing so that the target was off for one second and exposed for one second, in order to avoid adaptation effects and to make the task less difficult. A schematic depicting a subject's view of the visual target is shown in Figure 4A.

\section{Glare light source}

The characteristics of the glare light varied somewhat among the three tests (glare disability, photostress recovery, and

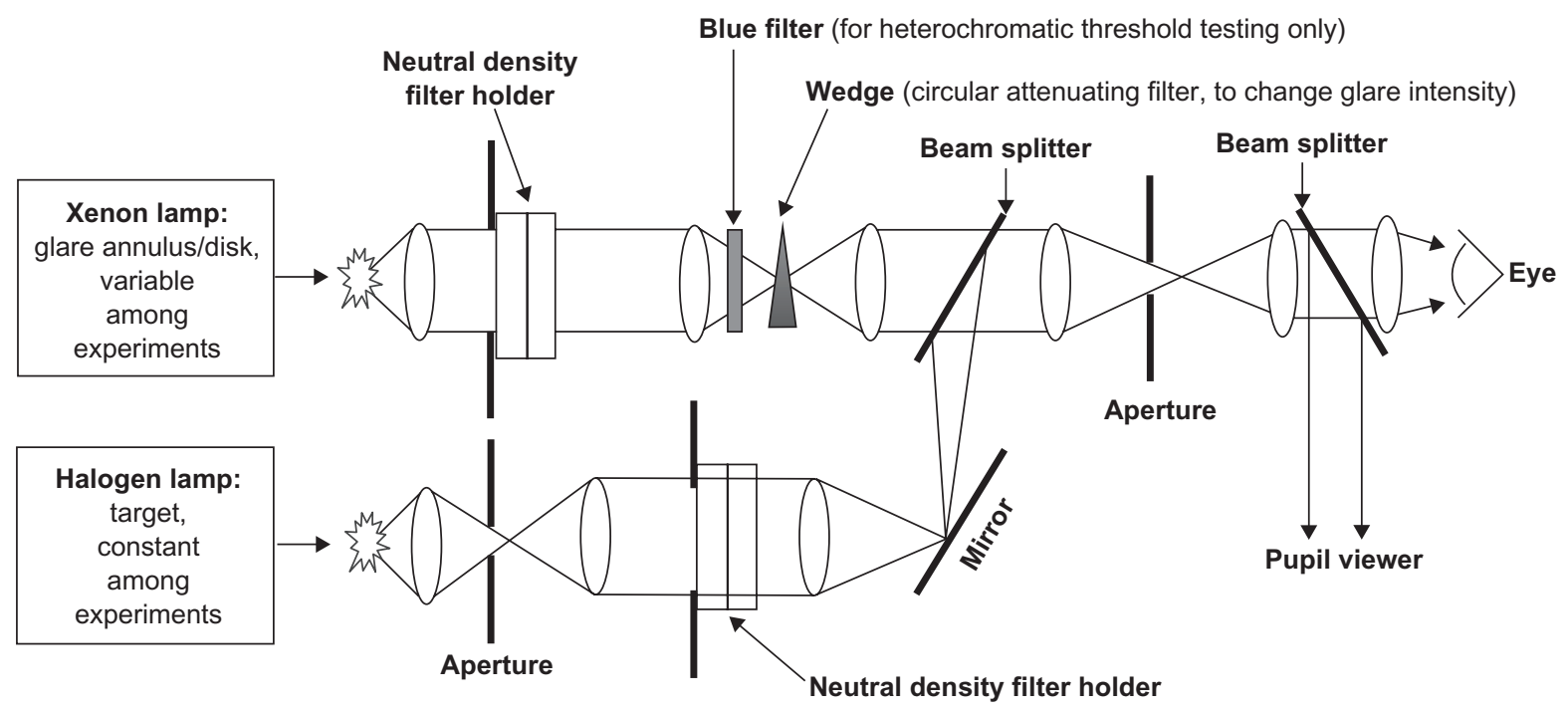

Figure 2 Schematic of the systems used for our dependent measures. The lenses were ultraviolet-coated, planoconvex achromats. 


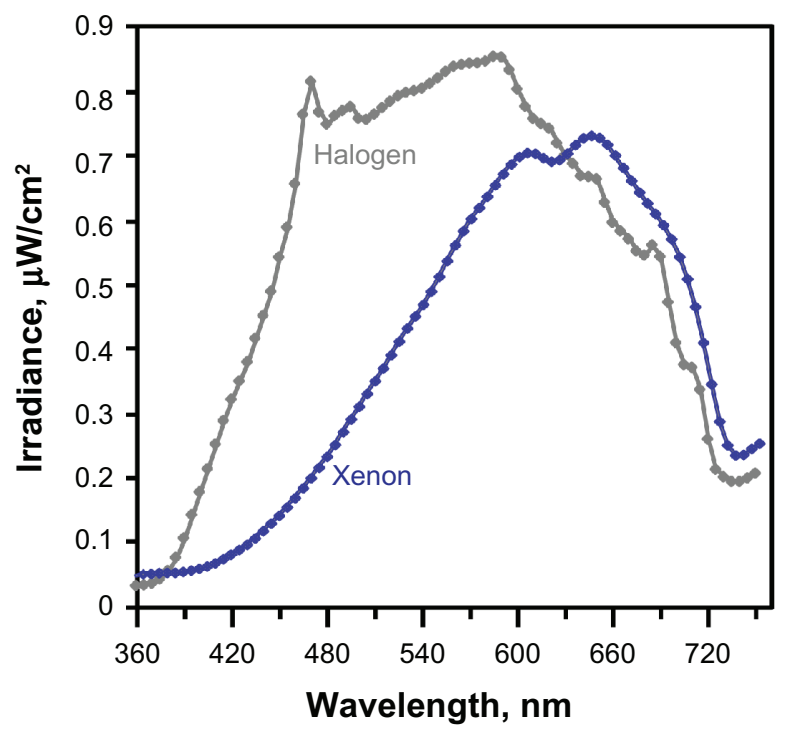

Figure 3 Gray trace: unattenuated emission spectrum of the halogen bulb that was used to create the target visual stimulus. Blue trace: unattenuated emission spectrum of the light in the xenon channel that was used to create the broad-band glare annulus and photostress condition.

heterochromatic contrast threshold). For all tests, the glare light originated from the $250 \mathrm{~W}$ xenon bulb of the dual-port source. The xenon source was modified to allow point-source illumination and was manipulated to produce either an annulus or a background field, depending on the test. The xenon source had an emission spectrum, as shown in Figure 3 (as assessed by the SpectraScan colorimeter). This xenon glare source appeared as a broad-band white light, with a CIE chromaticity of $\mathrm{u}^{\prime}=0.25, \mathrm{v}^{\prime}=0.53$.

\section{Visual testing}

The procedure for each assessment was explained to the subjects prior to testing using a standardized set of animated slides.

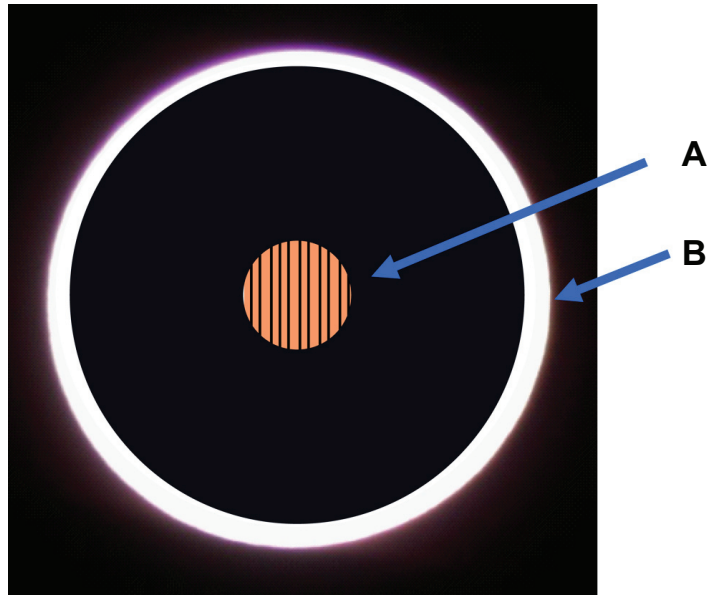

Figure 4 Schematic depicting a subject's view into the testing apparatus for the glare disability experiment. A) Visual target. B) Glare annulus.
Prior to each type of test, each subject was instructed to fixate on the center of the target stimulus, and the investigator aligned the optical system so that the arc image ( $2.5 \mathrm{~mm}$ diameter) was in focus in the plane of the subject's pupil. The investigator was masked to the identities of the IOLs during testing.

\section{Disability glare testing}

During disability glare testing, the xenon-channel spectrum was unfiltered and was set to produce an annulus with a $20^{\circ}$ inner diameter and $22^{\circ}$ outer diameter, as shown in Figure 4B. The subject first viewed the target surrounded by an annulus that had an intensity set at a level that was much too low to obscure the target stimulus. The technician then increased the intensity of the annulus via a neutral-density wedge until the subject stated that the target stimulus was no longer visible. The intensity of the annulus of light at that point was defined as the glare disability value. An ascending method of limits combined with the method of constant stimuli procedure was used. Five measures were taken per eye, unless a subject's values had more than 5\% variability, in which case up to four additional trials were conducted. If extra trials were conducted, all trials were averaged into the subject's mean result.

\section{Heterochromatic contrast threshold testing}

During heterochromatic threshold testing, the xenon source was filtered with an interference filter (half-power bandwidth $=8 \mathrm{~nm}$, Edmund Optics, Barrington, NJ, USA) in order to produce a monochromatic $430 \mathrm{~nm}$ field. The diameter of the background encompassed a $24^{\circ}$ visual angle, as shown in Figure 5. At the beginning of each test, the intensity of the

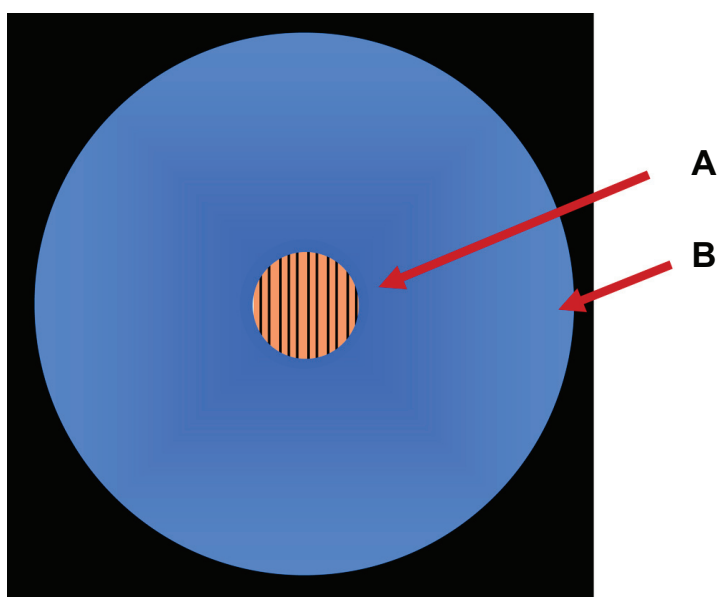

Figure 5 Schematic depicting a subject's view into the testing apparatus for the heterochromatic threshold testing experiment. A) Visual target. B) Background field. 
blue background was set at a level that was much too low to obscure the target stimulus. The technician then increased the intensity of the background until the subject stated that the target stimulus was no longer visible. An ascending method of limits was used. Once an approximate threshold had been determined, the method of constant stimuli was used to determine a precise threshold. Five trials were sufficient to derive accurate thresholds, but if a subject's values were excessively variable (ie, more than 5\% variability), up to four additional trials were conducted. If extra trials were conducted, all trials were averaged into the subject's mean result.

\section{Photostress recovery testing}

For the photostress recovery experiment, a $24^{\circ}$ diameter disk with an intensity of $5.0 \log$ trolands served as the photostress stimulus. A shutter from Vincent Associates (Rochester, NY, USA) was used to present the photostress stimulus. The target stimulus alone (without photostress) was presented for the subject to view for 20 seconds. Subjects were instructed to keep their eye open during the upcoming photostress exposure. The subject was then presented with the photostress for five seconds. If the investigator observed that the test beam was occluded by blinking or eye closure, the test was discarded. After the photostressor was discontinued, a stopwatch was started. Subjects were instructed to indicate when they could first perceive the target stimulus, and this duration was defined as the photostress recovery time. After early experiments showed that these measures were not reproducible for each subject (due to the inability of the retina to recover fully within a convenient amount of time), these measures were taken only once per eye, to ensure that measurements were taken from a naïve retina.

\section{Statistical analyses}

Comparisons for glare disability assessment, heterochromatic contrast threshold, and photostress recovery between IOL groups were performed using paired $t$-tests, at a level of significance of alpha $=0.05$. The data were averaged, including those with the additional trials, and standard deviation values were calculated. The mean values for glare disability and heterochromatic contrast threshold were compared, and the data are presented as log energy values $\left(\mu \mathrm{W} / \mathrm{cm}^{2}\right)$. For photostress, the analyses were performed on the logarithms, and the means and standard deviations of the log-scale values were then converted using antilogs, so as to convert these summary values to the original scale of measurement. For photostress recovery, the data are presented in seconds.
All results are reported as mean \pm standard deviation unless otherwise specified.

\section{Results Demographics}

A total of 52 subjects were enrolled, of whom 28 were women (54\%) and 24 were men (46\%). The study population had a mean age of $76 \pm 9$ years. All subjects had a control SA60AT lens in one eye. In the contralateral eyes, $50 \%$ of subjects (26 of 52) had a model SN60AT lens (spherical IOL with the blue-filtering chromophore), and $50 \%$ of subjects (26 of 52) had a model SN60WF lens (aspheric IOL with the blue-filtering chromophore). The average duration of pseudophakia before entering the study was $5.2 \pm 1.3$ years for the eyes with blue-filtering IOLs, and 5.6 \pm 1.3 years for the eyes with control SA60AT IOLs. The average duration between contralateral IOL implantations was $0.4 \pm 1.1$ years. Uncorrected and corrected distance visual acuities were similar in eyes with blue-filtering IOLs and eyes with control SA60AT IOLs, as shown in Table 1.

\section{Glare disability}

Significantly more light $(P=0.04)$ could be withstood by eyes with blue-filtering IOLs $\left(1.97 \pm 0.44 \log \mu \mathrm{W} / \mathrm{cm}^{2}\right)$ than by eyes with nonfiltering control IOLs $\left(1.88 \pm 0.43 \log \mu \mathrm{W} / \mathrm{cm}^{2}\right)$ before losing sight of the target, as shown in Figure 6. Due to variability in repeat measurements, which may have been caused by difficulty in aligning the subject with the optical axis of the system, five eyes with blue-filtering IOLs and five eyes with control IOLs required more than five tests per eye (up to nine trials per eye).

\section{Heterochromatic contrast threshold}

The mean heterochromatic contrast threshold was significantly better $(P=0.0003)$ in the blue-filtering IOL group $\left(0.36 \pm 0.43 \log \mu \mathrm{W} / \mathrm{cm}^{2}\right)$ than in the control SA60AT IOL

Table I Monocular distance visual acuities among groups, by model of intraocular lens

\begin{tabular}{|c|c|c|}
\hline & $\begin{array}{l}\text { Blue-filtering IOL } \\
\text { group } n=52\end{array}$ & $\begin{array}{l}\text { Control SA60AT } \\
\text { group } n=52\end{array}$ \\
\hline \multicolumn{3}{|c|}{ Uncorrected DVA, logMAR } \\
\hline $\begin{array}{l}\text { Mean } \pm \text { standard deviation } \\
\text { (worst, best) }\end{array}$ & $\begin{array}{l}0.2 \pm 0.2 \\
(0.9,-0.1)\end{array}$ & $\begin{array}{l}0.2 \pm 0.2 \\
(0.7,-0.1)\end{array}$ \\
\hline \multicolumn{3}{|c|}{ Corrected DVA, logMAR } \\
\hline $\begin{array}{l}\text { Mean } \pm \text { standard deviation } \\
\text { (worst, best) }\end{array}$ & $\begin{array}{l}0.03 \pm 0.09 \\
(0.3,-0.1)\end{array}$ & $\begin{array}{l}0.02 \pm 0.09 \\
(0.4,-0.2)\end{array}$ \\
\hline
\end{tabular}

Abbreviations: DVA, distance visual acuities; IOL, intraocular lens; logMAR, logarithmic minimum angle of resolution. 


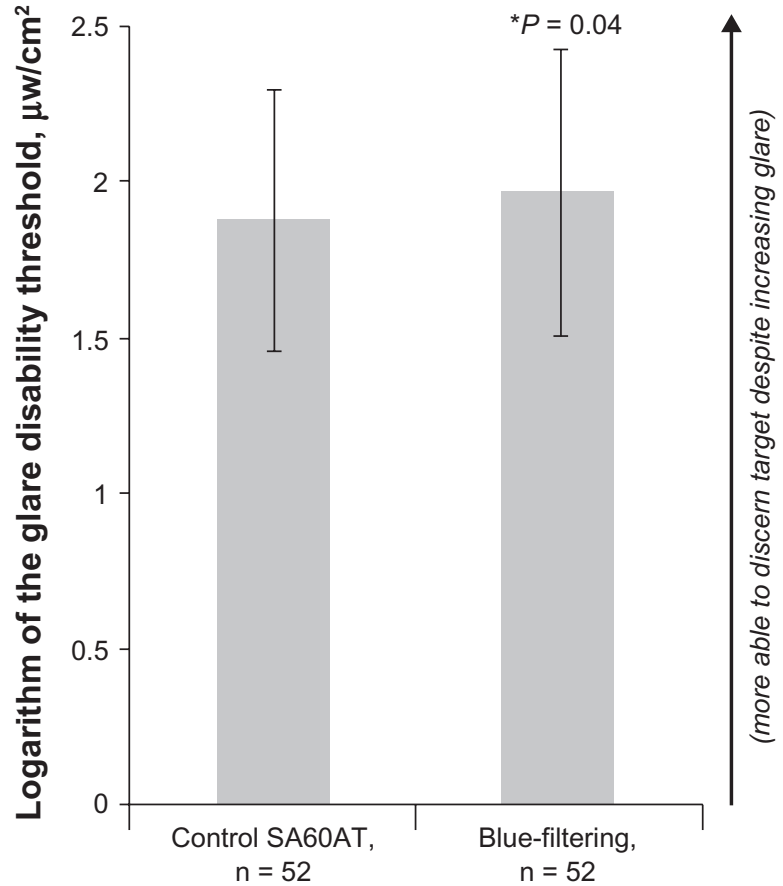

Figure 6 Glare disability (the amount of energy in an annulus necessary to veil a central target). Values are presented as mean \pm standard deviation.

group $\left(0.15 \pm 0.49 \log \mu \mathrm{W} / \mathrm{cm}^{2}\right)$, as shown in Figure 7 . Due to variability in repeat measurements, which may have been caused by difficulty in aligning the subject with the optical system, eight eyes with blue-filtering IOLs and five eyes with control IOLs required more than five tests per eye (up to nine trials per eye).

\section{Photostress recovery}

The geometric mean transformed photostress recovery time was significantly faster $(P=0.02)$ in the group with the bluefiltering IOLs ( $21 \pm 3$ seconds) than in the group with the nonfiltering IOLs (26 \pm 3 seconds), as shown in Figure 8 . A similar result was obtained $(P=0.023$, for a one-tailed test) when analyzing the raw data using a Student's $t$-test (with corrections for unequal variance). Photostress recovery times were analyzed for 100 eyes (50 blue-filtering IOLs and 50 nonfiltering IOLs) of the total cohort of 104 eyes. Data were missing for four eyes due to head movement or blinking during the test. For one additional eye in the blue-filtering IOL group, no photostress recovery time was recorded because the time during which photostress recovery should be recorded had exceeded six minutes without the subject reporting the ability to discern the target. It was suspected that this subject may have had covert retinal pathology that could have affected photostress recovery. Photostress recovery times of up to 407.4 seconds had been observed for

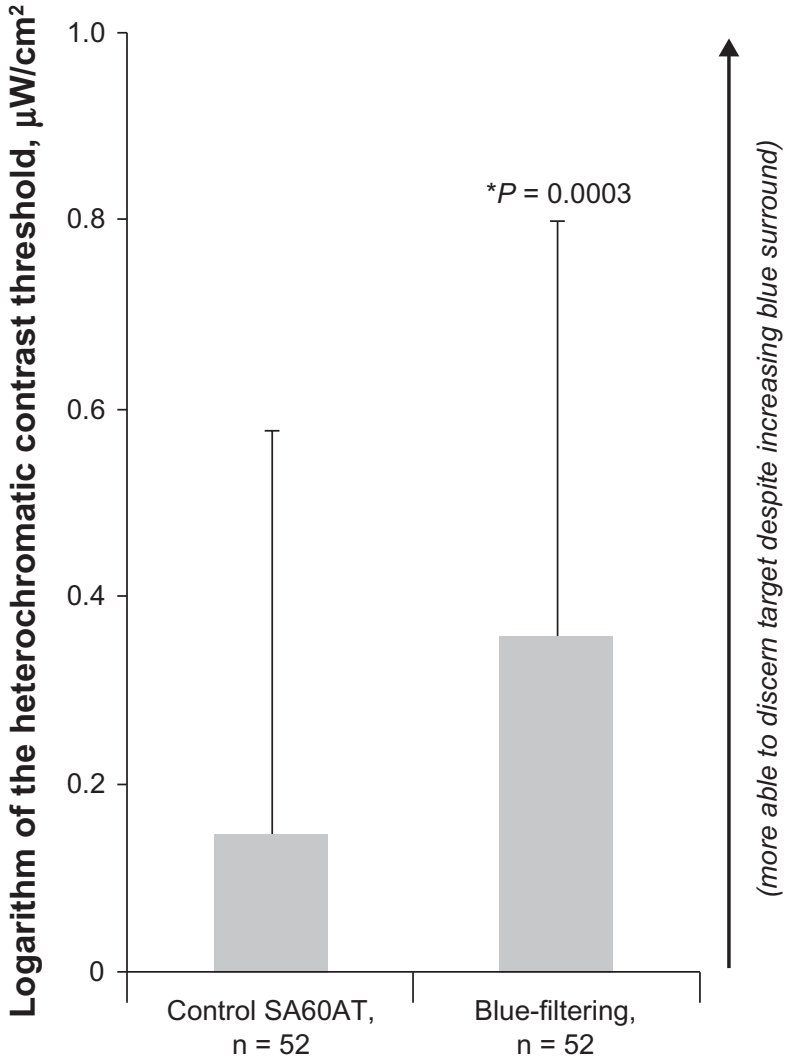

Figure 7 Heterochromatic contrast threshold (the amount of energy in the $430 \mathrm{~nm}$ background that forced the subject to lose sight of the central target). Values are presented as mean \pm standard deviation, with error bars shown unidirectional for clarity.

the other eyes, so the decision was made to impute the value of 410 seconds into the unrecorded parameter, in order to preserve the information that the photostress recovery time for this eye was long.

\section{Discussion}

The results of the present study are consistent with the conclusion that the filtering of blue light provided by the AcrySof Natural IOLs has distinct effects on visual performance.

Glare disability was statistically different between the group with blue-filtering IOLs and the group with nonfiltering IOLs. The intense light entering the eye from the glare source was scattered forward by the intraocular media, causing a veiling luminance over the visual target. Analogous situations could occur in the real world when a driver is looking into oncoming headlights. By filtering such light, the visibility of a target within an individual's sight line would be improved, as was demonstrated by the model in this study. This improvement would be directly related to the amount of energy absorbed. As shown in Figure 3, our glare source contained some energy in the 400-450 $\mathrm{nm}$ region, 
where absorbance by the blue-filtering IOLs is higher than absorbance by the nonfiltering IOL (see Figure 1). The extent to which an intraocular filter absorbs the scattering source should determine the degree to which that filter will reduce glare disability. Consistent with this presumed mechanism, past studies that presented stimuli with relatively little short-wave energy to subjects with blue-filtering IOLs have reported minimal effects on glare disability. ${ }^{22}$ Under more naturalistic conditions (eg, outdoors in the sunlight, which contains more short-wave energy), the effect of a blue-light filter on glare disability could be even more substantial.

Using the same xenon light source, we also found a large effect on photostress recovery. On average, visual function was recovered five seconds faster by the eyes with the bluefiltering IOLs than by the eyes with the non-blue-filtering IOLs. The contralateral design of the study was optimal for studying this parameter, as many factors influence the regeneration kinetics of bleached photopigment, eg, age and disease state. Such a difference could be quite significant. For example, recovering visual function five seconds faster translates to 440 feet when driving at 60 miles per hour. This could mean the difference between having an accident or not when impaired by bright oncoming headlights. The fact that we found a stronger effect for photostress recovery compared with glare disability may be due to the intense light

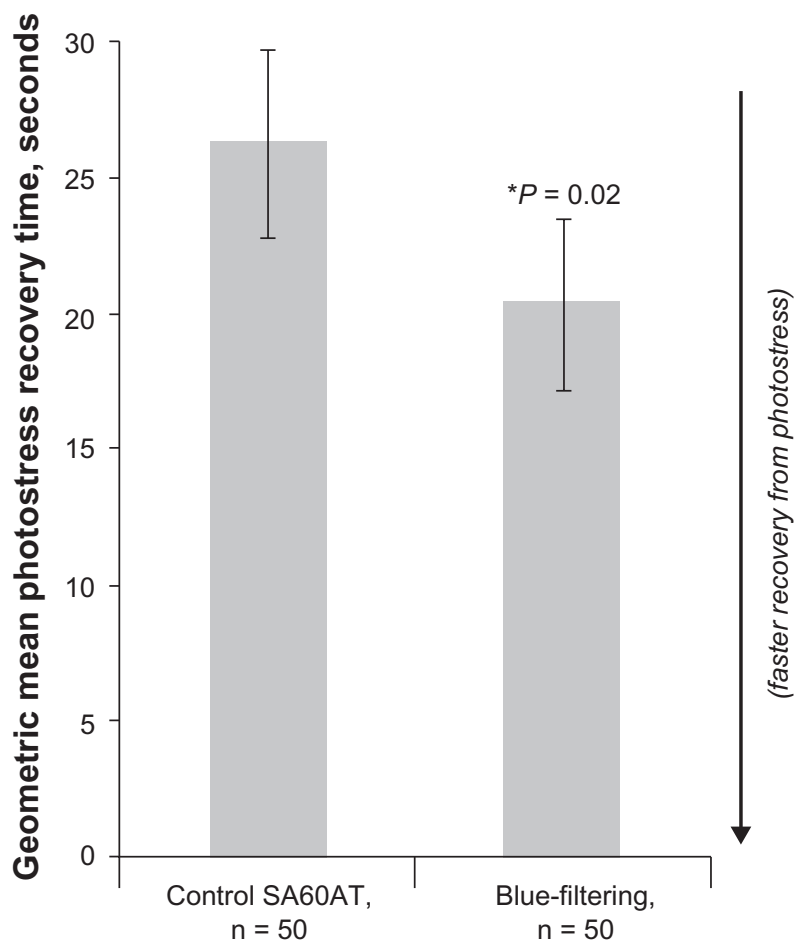

Figure 8 Photostress recovery durations (amount of time required to regain sight of the central target after exposure to photostress). Values are presented as geometric mean \pm standard deviation. levels that were presented in the photostress condition. Even a small amount of short-wave energy is probably significant if the bleaching source is sufficiently intense.

The spectrum of the xenon arc lamp that produced the glare and photostress conditions in this study was applicable as a model both for nighttime driving and for daytime function. Xenon headlights are available for many models of automobiles. Moreover, the spectrum of the xenon arc lamp (see Figure 3) is a good approximation of midday sunlight ${ }^{23}$ (see Figure 9). Broad-band white light sources, such as the one used in this study, are thus common in everyday life.

In addition to the white-light experiments in this study, heterochromatic contrast thresholds were also significantly better in the blue-filtering IOL group than in the control IOL group when using a short-wave background and a mid-wave target. Given the neural mechanisms underlying edge detection, any alteration of an image that enhances contrast of a given target relative to its surrounding spectral environment should improve detectability of that target. Hence, under the right wavelength conditions, and if the eye acted as a simple detector, a blue-filtering IOL would improve contrast, by definition. The wavelength conditions are simply that the blue-filtering lens absorbs one side of a chromatic border more than the other side and hence enhances the difference across the edge. Our study has shown that a blue-filtering

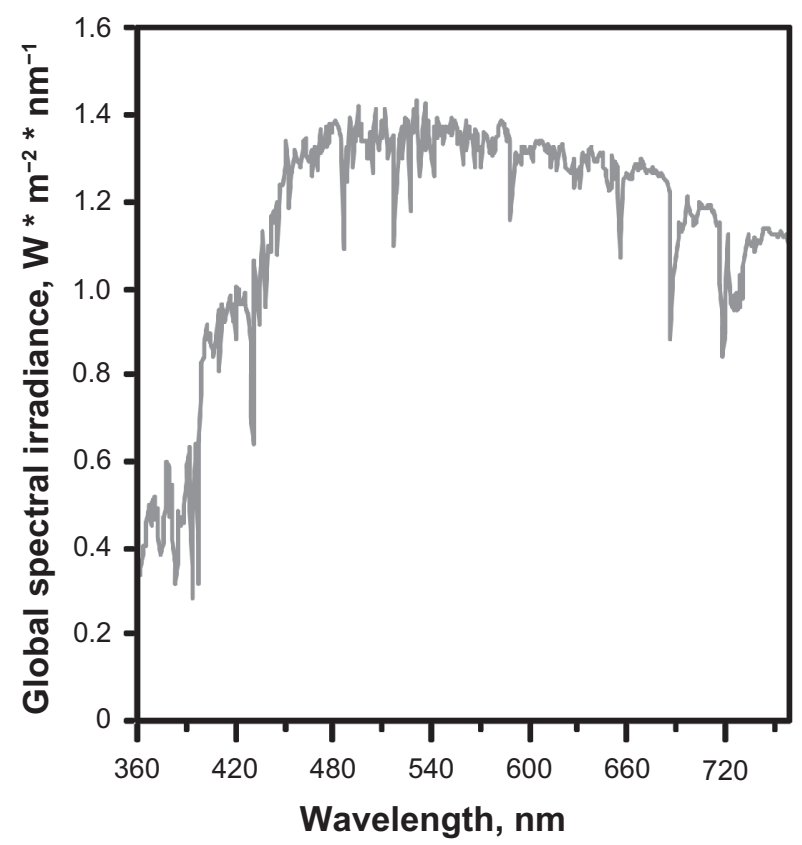

Figure 9 Spectrum of daytime sunlight.

Copyright (C) 2010, ASTM international. Reproduced with permission from ASTM GI73-03el Standard Tables for Reference Solar Spectral Irradiances: Direct Normal and Hemispherical on $37^{\circ}$ Tilted Surface. A copy of the complete standards may be obtained from ASTM, www.astm.org. 
IOL enhanced contrast as directly as the simple optics of contrast would predict.

Increased heterochromatic contrast thresholds have practical ecologic significance. Recent data have shown that color borders (ie, isoluminant edges) are probably very common in the natural environment, ${ }^{24}$ and therefore chromatic differences likely play a significant role in object detection in the real world. This is particularly true when viewing objects at a distance, because distance would tend to equalize differences in luminance that would have defined edges if they were closer. A blue-filtering lens would recreate a luminance edge when it absorbed one side of a chromatic border more than the other side. In this study we used a $430 \mathrm{~nm}$ background with a mid-long-wave target (halogen). Is this kind of stimulus generalizable? In an analysis of vision in the natural environment, Wooten and Hammond argued that such a simple stimulus was a good characterization of vision outdoors. ${ }^{15}$ Rayleigh scatter and blue haze often create blue backgrounds when viewing objects at a distance, such as an airplane on a blue sky. The opposite effect occurs for objects directly within the sight path, ie, light scatters out of the sight line, causing a shift toward mid-long-wave light. Hence, we are often viewing longer-wave targets on shortwave backgrounds.

Vision with good heterochromatic contrast is also necessary indoors. Vision scientists have noted that black and white documents have been the subject of frequent indepth studies, but chromatic documents are now becoming an issue due to the large-scale appearance of web pages in color. ${ }^{25}$ Experimenters who tested the readability of chromatic web pages with healthy phakic subjects noted that certain chromatic situations were counterproductive for good visual performance and produced a discomfort that was "similar to that produced by dazzling, a phenomenon when using an insufficiently shaded and incorrectly placed light source". ${ }^{25}$ It was already known that blue-filtering AcrySof IOLs do not adversely affect color vision. ${ }^{26}$ Our study shows that, to the contrary, these IOLs increase heterochromatic contrast thresholds.

Given our study design, it is likely that the mechanism underlying our results was wholly due to the spectral properties of the blue-filtering IOL. However, the blue-light filtering could also have induced other changes that could further enhance the visual effects. For example, Nolan et al recently found that implantation of a blue-filtering IOL was associated with increases in another intraocular blue-light absorber, macular pigment, when compared with implantation of a nonfiltering IOL. ${ }^{27}$ Macular pigments influence glare disability and photostress recovery times ${ }^{4,20}$ and improve contrast enhancement (when targets are presented with a $460 \mathrm{~nm}$ background, a wavelength that matches the peak absorbance of macular pigments). ${ }^{28}$ If macular pigment was denser in the eyes containing the blue-filtering IOLs, this could explain at least part of the visual effects we measured. Whatever the mechanisms of visual enhancement with bluefiltering IOLs, the benefits were significant for all outcomes measured in this study.

In conclusion, our results are consistent with the hypothesis that the blue-filtering AcrySof IOLs (with the specific absorption spectra conferred by the proprietary chromophore) reduced disability due to glare, improved the heterochromatic contrast threshold, and improved recovery from photostress, under the spectral conditions presented in these experiments.

\section{Acknowledgements}

The authors would like to acknowledge the following participating clinical investigators: Robert Lehmann MD (Lehmann Eye Center, Nacogdoches, TX, USA); James Davison MD (Wolfe Eye Clinic, Marshalltown, IA, USA); W Andrew Maxwell MD, PhD (Fogg, Maxwell, Lanier and Remington, Fresno, CA, USA); Stephen F. Brint MD (Brint Custom Vision, Metairie, LA, USA); and David A. Nethery MD (Nethery Eye Associates, Fort Worth, TX, USA), and Laura Fletcher MS (Vision Sciences Laboratory, University of Georgia, Athens, GA, USA) for assistance.

\section{Disclosures}

This study was supported by Alcon Research Ltd, Fort Worth, TX, USA. BRH and LMR have no financial or proprietary interest in any products in this manuscript. SS was an employee of Alcon during the conduct of the study. SFB is a consultant to Alcon.

\section{References}

1. Walls GL, Judd HD. The intra-ocular colour-filters of vertebrates. Br J Ophthalmol. 1933;17(11):641-675.

2. Walls GL, Judd HD. The intra-ocular colour-filters of vertebrates. Br J Ophthalmol. 1933;17(12):705-725.

3. Stringham JM, Fuld K, Wenzel AJ. Action spectrum for photophobia. $J$ Opt Soc Am A Opt Image Sci Vis. 2003;20(10):1852-1858.

4. Stringham JM, Hammond BR Jr. The glare hypothesis of macular pigment function. Optom Vis Sci. 2007;84(9):859-864.

5. Luckiesh M. Color and vision. Color and Its Applications. 2nd ed. New York, NY: D. van Nostrand Co; 1915.

6. Luria SM. Vision with chromatic filters. Am J Optom Arch Am Acad Optom. 1972;49(10):818-829.

7. Wolffsohn JS, Cochrane AL, Khoo H, Yoshimitsu Y, Wu S. Contrast is enhanced by yellow lenses because of selective reduction of shortwavelength light. Optom Vis Sci. 2000;77(2):73-81. 
8. Yap M. The effect of a yellow filter on contrast sensitivity. Ophthalmic Physiol Opt. 1984;4(3):227-232.

9. Leat SJ, North RV, Bryson H. Do long wavelength pass filters improve low vision performance? Ophthalmic Physiol Opt. 1990;10(3): 219-224.

10. Hovis JK, Lovasik JV, Cullen AP, Kothe AC. Physical characteristics and perceptual effects of "blue-blocking" lenses. Optom Vis Sci. 1989; 66(10):682-689.

11. Leguire LE, Suh S. Effect of light filters on contrast sensitivity function in normal and retinal degeneration subjects. Ophthalmic Physiol Opt. 1993;13(2):124-128.

12. Zigman $\mathrm{S}$. Vision enhancement using a short wavelength light-absorbing filter. Optom Vis Sci. 1990;67(2):100-104.

13. Zigman S. Light filters to improve vision. Optom Vis Sci. 1992;69(4): 325-328.

14. Boettner E, Wolter J. Transmission of the ocular media. Invest Ophthalmol Vis Sci. 1962;1(6):776-783.

15. Wooten BR, Hammond BR. Macular pigment: Influences on visual acuity and visibility. Prog Retin Eye Res. 2002;21(2):225-240.

16. Hammond BR, Bernstein B, Dong J. The effect of the AcrySof natural lens on glare disability and photostress. Am J Ophthalmol. 2009;148(2):272-276.

17. Sparrow JR, Miller AS, Zhou J. Blue light-absorbing intraocular lens and retinal pigment epithelium protection in vitro. $J$ Cataract Refract Surg. 2004;30(4):873-878.

18. Hammond BR, Bernstein B, Dong J. The effect of the AcrySof natural lens on glare disability and photostress. Am J Ophthalmol. 2009;148(2):272-276.

19. Renzi L, Hammond B. The effect of macular pigment on contrast thresholds. J Vision. 2010; In press.
20. Stringham JM, Hammond BR. Macular pigment and visual performance under glare conditions. Optom Vis Sci. 2008;85(2):82-88.

21. Pointer M. A comparison of the CIE 1976 colour spaces. Color Res Appl. 1981;6(2):108-118.

22. Muftuoglu O, Karel F, Duman R. Effect of a yellow intraocular lens on scotopic vision, glare disability, and blue color perception. J Cataract Refract Surg. 2007;33(4):658-666.

23. ASTM G173-03e1, Standard Tables for Reference Solar Spectral Irradiances: Direct Normal and Hemispherical on $37^{\circ}$ Tilted Surface. West Conshohocken, PA: American Society for Testing and Materials, ASTM International; 2003.

24. Hansen T, Gegenfurtner KR. Independence of color and luminance edges in natural scenes. Vis Neurosci. 2009;26(1):35-49.

25. Pescio C, de Mattiello M, Alvarez R. Readability of chromatic documents. In: Caivano JL, editor. AIC 2004 Color and Paints, Proceedings, Interim Meeting of the International Color Association. Porto Alegro, Brazil: International Color Association; 2005.

26. Rodríguez-Galietero A, Montés-Micó R, Muñoz G, Albarrán-Diego C. Comparison of contrast sensitivity and color discrimination after clear and yellow intraocular lens implantation. J Cataract Refract Surg. 2005;31(9):1736-1740.

27. Nolan JM, O'Reilly P, Loughman J, et al. Augmentation of macular pigment following implantation of blue light-filtering intraocular lenses at the time of cataract surgery. Invest Ophthalmol Vis Sci. 2009;50(10): $4777-4785$.

28. Renzi LM, Snodderly DM, Hammond BR Jr. Reduction of surround suppression and enhancement of discriminability by macular pigment. Invest Ophthalmol Vis Sci. 2009;50(5):1703.
Clinical Ophthalmology

\section{Publish your work in this journal}

Clinical Ophthalmology is an international, peer-reviewed journal covering all subspecialties within ophthalmology. Key topics include: Optometry; Visual science; Pharmacology and drug therapy in eye diseases; Basic Sciences; Primary and Secondary eye care; Patient Safety and Quality of Care Improvements. This journal is indexed on PubMed

Submit your manuscript here: http://www.dovepress.com/clinical-ophthalmology-journal

\section{Dovepress}

Central and CAS, and is the official journal of The Society of Clinical Ophthalmology (SCO). The manuscript management system is completely online and includes a very quick and fair peer-review system, which is all easy to use. Visit http://www.dovepress.com/testimonials. php to read real quotes from published authors. 